\title{
NARRATIVAS E TECIDOS BORDADOS
}

Thaís Fernanda Salves de Brito ${ }^{1}$

UFRB, Santo Amaro-BA, Brasil

O objetivo deste artigo é apresentar bordados que transcendem a noção de mercadorias, tornando-se um objeto singular e um bem cultural, fruto de sobreposições artísticas que unem materialidade e sensibilidade, mobilidades e diásporas, leituras pessoais e coletivas sobre as práticas artesanais de produção. Para isso, o ponto de partida deste ensaio são as narrativas das bordadeiras de Caicó-RN acerca dos discursos que elas organizam sobre as rotas estéticas de seus bordados e como se revelam nas representações estéticas dos tecidos. Por fim, propõe-se uma reflexão sobre a produção antropológica acerca de alguns elementos ligados à cultura material têxtil.

Palavras-chave: cultura material têxtil, narrativas, diásporas, indumentária, artefatos

\section{INTRODUÇÃO}

Em 2013, ao visitar o museu Victoria \& Albert, em Londres, no setor dedicado à cultura material indiana, deparei-me com um delicado pedacinho de linho finíssimo bordado com pequenas flores. O que me chamou a atenção, na verdade, foi o estilo da flor e forma da composição daquele bordado. Imediatamente, aquele pedaço de pano ativou a minha memória, a minha experiência com os bordados e com os discursos que ouvi inúmeras vezes sobre a herança do bordado feito em Caicó, cidade conhecida por seus bordados coloridos, plenos de flores, folhas, pássaros e arabescos, revelando uma interpretação sui generis da natureza, por meio de representações que subvertem a aridez usualmente projetada para a região (Brito 2011). ${ }^{2}$

1 Contato da autora: tfsbrito@yahoo.com.br.

2 Caicó é parte da região do Seridó. Localiza-se na zona da caatinga do estado do Rio Grande do Norte, e compõe uma área também nomeada como Polígono das Secas. A cidade fica a $263 \mathrm{Km}$ de Natal, capital do estado, um importante destino turístico brasileiro. Segundo o IBGE, tem uma população estimada 67.554 pessoas (2018), habitando uma área de $1.228,57 \mathrm{Km}^{2}$. 
Foi interessante observar que naquele pedaço de tecido - que depois vim saber que se tratava de um fragmento de turbante - havia uma composição de flores bem pequenas, bordadas em um cor-de-rosa suave, com detalhes em verde, formando as delicadas folhas que se somavam à repetida composição do desenho. Essas flores eram idênticas às que se encontram com frequência no nordeste brasileiro, principalmente nos estados da Bahia, Pernambuco, Rio Grande do Norte e Ceará. Para se formar este desenho de flor é preciso bordar, em ponto cheio, cinco círculos pequenos, perfeitos e sequentes, criando quase que um novo círculo de pequenas bolinhas. O bom uso desta técnica de composição a partir deste ponto simples - ponto cheio - cria uma pequena e singela flor com cinco pétalas. Várias destas flores formavam delicadas linhas compostas por cachos de flores, ornamentando assim, delicadamente, o tecido.

Para além da similaridade técnica e estética da peça, o que me intrigou foi que em Caicó, e na região do Seridó, este ponto é comumente conhecido como "rosinha do Ceará", nome dado a uma clara referência aos bordados que são realizados no estado do Ceará, também lugar de produção ativa de bordados. Havia em mim o registro inconsciente de que esta composição havia sido feita na região que nomeia o ponto do bordado. Trata-se de uma técnica ordinária, ensinada para quem está aprendendo a bordar, compartilhada em muitos lugares e que serve como base para formar outras composições similares, ligando-a a outros tipos e estilos de bordados feitos no país, praticamente como um todo.

Foi uma fração de tempo bem rápida. Voltei, então, à vitrine e, ao olhar a descrição da peça, descobri que se tratava de um fragmento original do século XVIII, trazido da Índia pelos britânicos. Como o bordado indiano produzido há mais de 300 anos poderia ser idêntico ao bordado nordestino? Retomei, então, os outros desenhos expostos nesta mesma sala do museu, e lá percebi desenhos, estilos, formas e uso de cores, enfim, um estilo que repercutia em outros artefatos, não necessariamente nos tecidos, mas que contribuem com a composição do repertório da cultura material têxtil que, possivelmente, influenciou e foi influenciada pelo contato de outras expressões artísticas (inclusive, outros têxteis) e que, por alguma razão, encontrou um sentido em alguns lugares do Brasil.

Ingold (2007), ao fazer sua "antropologia comparativa da linha", parte da seguinte questão: "O que caminhar, tecer, observar, cantar, contar uma história, desenhar e escrever têm em comum?", sua resposta é: "todas estas ações procedem em linhas” (Ingold 2007: 1). Linhas nos interessam. Sejam as linhas entrelaçadas e padronizadas da tecelagem, fundamentais para se compor um tecido; ou as linhas do bordado que percorrem e repousam sobre tecidos vários formando um "mosaico de traços" e criando outras possibilidades estéticas ao seu suporte; ou ainda, as linhas das rendas cujos "fios se transformam em traços e os traços em fios" produzindo em seu vai-e-vem uma "circunstância na qual as superfícies passam a existir" (Ingold 2007: 52). Linhas nos interessam porque falam de movimentos e de transformações.

A cultura material têxtil é fruto de movimentos e de transformações, por isso engloba a produção criativa de materiais "fabricados através de algum tipo de tecimento, manufaturados pelo entrelaçamento dos fios e que ganham coesão por meio de tratamentos mecânicos ou químicos" (Neira 2011: 285). São artefatos que possuem, ainda, uma dimensão visual importante. Seus produtores são usualmente anônimos e seus produtos estão presentes na vida cotidiana. Ainda que seja uma experiência estética realizada com base em materiais que são entendidos como menores e com funções utilitárias demarcadas (se comparados à high art), produzir e con- 
sumir tecidos artesanais, rendas e bordados tem como função social "diferenciar e/ou humanizar ambientes e pessoas" (Neira 2011: 285).

Os tecidos e seus ornamentos apresentam uma lógica estética única que ocorre a partir deste elo interessante entre coisas (tecidos), referências, objetos e pessoas (bordadeiras e consumidores), fornecendo um olhar sui generis para as formas de produção e de circulação capitalista. Trata-se de uma experiência artística que se estabelece a partir do acesso aos repertórios coletivos, ao mesmo tempo em que se busca a distinção nas esferas públicas e privadas.

Essa experiência artística estabelece, ainda, modelos de humanização com o meio, ao bordar, por exemplo, elementos da natureza, como flores e folhas, com traços arredondados e cores suavizadas, isso, sem tratar das representações imagéticas e das referências em que não se tem um ponto específico de sua origem, como no caso da "rosinha do Ceará", mas que promove uma série de outras conexões visuais com bordados de outros lugares. Enfim, a cultura material têxtil se apresenta em objetos que, além de bonitos, são antropologicamente fascinantes e reúnem perspectivas históricas, referências múltiplas e, ainda, se apresentam (re)significados, seja por meio da elaboração técnica, seja pelos discursos que são tecidos sobre estes mesmos objetos por aqueles que o produzem e o consomem e, no caso específico desta investigação, provocam uma reflexão entre antropologia e cultura material têxtil.

Não é, portanto, de se estranhar que uma série de questões passou a se formar naquele momento, a partir do pedacinho do tecido. Por exemplo, como a estética de determinados artefatos se comunicam entre si e por que, mesmo diante de referências culturais tão distintas, há uma estética na produção artesanal dos têxteis e de seus adornos que revela uma experiência ontológica similar? Poder-se-ia refletir sobre os processos de fricção cultural, interpelados pela agência dos objetos; ou, ainda, por que, apesar da industrialização massiva, tecidos artesanais, rendas e bordados seguem como parte de um circuito que apresenta outras lógicas para além de uma concepção restrita sobre mercadoria?

Infelizmente, neste ensaio, não será possível explorar todas as questões que foram postas acima, mas elas servem como mote de reflexão, tendo como ponto de partida as narrativas sobre as representações estéticas nos tecidos. Parte-se do pressuposto que há uma sobreposição artística que une materialidade e sensibilidade, mobilidades e diásporas, leituras pessoais e coletivas sobre as práticas artesanais de produção, especialmente do bordado.

Este ensaio está dividido em três seções, somadas a esta breve introdução. A primeira seção, intitulada "Bordado: objeto singular" propõe uma reflexão sobre o quanto os bordados rompem com as lógicas que regem as práticas usuais de consumo. Tratam-se de objetos que permitem acessos a conteúdos simbólicos, emergência de algumas noções de identidade e das questões de autenticidade. A seção "Mulheres, bordados e circuitos" propõe um olhar pontual para a produção de bordados como uma experiência de formação, de comunicação e de criatividade que se estabelece a partir da vida doméstica e dos trabalhos das mulheres (sejam eles, os bordados, realizados em casa ou nas fábricas); além disso, apresenta uma forma de ação econômica atrelada às noções maussianas sobre a dádiva. Por fim, as considerações finais propõem breves reflexões sobre possibilidades de análise e aprofundamento.

Este ensaio foi desenvolvido a partir das narrativas das artesãs caicoenses. Interessou-nos percorrer os discursos que elas organizam sobre as rotas estéticas que consolidam os estilos de 
seus trabalhos (nas performances das feiras e em alguns depoimentos que foram colhidos no desenvolvimento da pesquisa, realizada desde 2007), bem como as possíveis reflexões para as quais a antropologia nos conduz diante a singularidade de determinados objetos.

\section{BORDADO: OBJETO SINGULAR}

Em Caicó, no final do mês de julho ocorre a Festa de Sant'Anna. Dias de festa que alternam fervor religioso (católico) e festejos de cunho profano "que se entrelaçam na construção da identidade coletiva" (Cavignac; Alves 2007: 8). Recordando as coisas da terra, as histórias e os feitos milagrosos da Santa, a festa se revela como um poderoso veículo de memória e de ação coletiva, de espaço de narrativa e de performances em torno do bordado, que ocupa um lugar central na festa.

É nítido que o bordado:

(...) está no centro da festa, nos rituais religiosos, decorando também o entorno. Afinal, é preciso embelezar a casa para receber a família durante os festejos. E, em Caicó, ter uma casa bonita significa dispor de bordados para enfeitá-la. Mas, e é fundamental, o que valoriza a decoração não é um bordado qualquer, mas 'um bordado com assinatura', realizado por uma boa bordadeira, capaz de assinalar distinção social. (Brito 2011: 245)

Ao partirmos do pressuposto que a cultura se manifesta, dentre outras formas, nos artefatos, há nestes objetos um lócus de significação no mundo social (Bittencourt 1996: 98). Como a arte, trata-se de uma forma de representação, ligada à emoção estética, explicitamente construída, e que conduz a uma subjetividade (Severi 2011).

Os bordados, como um bem de consumo prestigioso naquela região, correspondem a uma forma de ação simbólica, uma tentativa de corresponder às expectativas de uma imagem coletiva (Gell 2008). Vale destacar que, para Baudrillard (2002), os objetos são vias de acesso para os sistemas simbólicos, assim como o são as práticas de consumo. Desta forma, os têxteis artesanais e seus ornamentos, como parte do universo da cultura material, apontam para sistemas simbólicos e podem ser entendidos como um resultado visível de técnicas e de práticas sociais comunicando-se com padrões e perspectivas mais amplas e que estão em constante circulação.

Estes objetos se organizam a partir de racionalidades e de subjetividades que lhes são peculiares (Queiroz 2011), apresentam tradições e experiências sobre a criação e sobre a reprodução dos modos de produzir, difundir e fazer circular certas mercadorias (Borges 2011). Pertencem a um circuito econômico que atravessa séculos, têm valor de uso e troca, porém ultrapassam as regras restritas do fluxo econômico.

Ao acompanhar as bordadeiras em três feiras distintas para venda de bordados (Gift FairSão Paulo, Feira Internacional de Artesanato/FIART-Natal e Feira de Artesanato do Seridó/ FAMUSE-Caicó), observou-se que a circulação dos bordados em um circuito estritamente comercial, cujos impactos são explícitos na cadeia produtiva e na vida econômica da região do Seridó, é marcada por uma narrativa específica. As bordadeiras, nestes contextos do comércio, ao venderem suas peças não as apresentam como simples mercadorias, no sentido restrito do termo. 
Para ser mais explícita, o valor de um bordado, por exemplo, não é dado na "contabilização" do tempo dedicado à tarefa, dos recursos investidos e da demanda do mercado, mas sim em quem fez, o lugar de origem, os possíveis usos e impactos que as peças podem causar, e, principalmente, o quanto essas peças falam da região do Seridó. Ou seja, esses bordados, na verdade, "portam significados, convenções, narrativas e agenciamentos vários, vinculando as pessoas que os produzem e desenhando um fluxo de relações" (Brito 2011: 235).

Tanto no contexto da festa quanto nas feiras, a origem portuguesa dos bordados de Caicó é frequentemente referida pelas bordadeiras, como uma herança das primeiras colonizadoras na formação do espaço seridoense. E, em duas circunstâncias, essa narrativa é muito importante. A primeira ocorreu em um encontro com as bordadeiras de Caicó com as provenientes na Ilha da Madeira, em uma feira de artesanato que aconteceu em Portugal, como veremos adiante. A segunda circunstância em que essa narrativa se torna ainda mais intensa é quando o bordado está em circulação, nas feiras ou nas festas, onde noções de identidade e de autenticidade se tornam muito importantes.

A experiência etnográfica da pesquisa sobre os bordados de Caicó revelou uma série de especificidades que circundam a prática artesanal seridoense, dentre elas, a ordenação dos processos de sociabilidade em torno da produção dos bordados, de formação da bordadeira, bem como das formas de circulação das peças. No entanto, sem sombra de dúvidas, o maior impacto foi observar como essa experiência estética produz bordados cheios de vida que reinterpretam e subvertem as imagens e os estigmas de miséria, de infertilidade, de rudeza e de ausência, usualmente relacionados àquela região, em virtude das interpretações sobre a natureza específica da caatinga e sobre os modelos de vida sertaneja, e como essas características se apresentam em uma relação identitária.

Os bordados feitos em Caicó estão ligados à terra onde são produzidos, simultaneamente são representantes e intérpretes da região. E, em meio esta constante mobilidade, emergem conceitos como autenticidade, pertencimento e patrimônio, principalmente em situações específicas de deslocamento espacial e de encontro com personagens, lugares e contextos que não são parte do contexto original da produção daqueles bordados, como, por exemplo, ao narrar a produção de bordado para uma pesquisa em antropologia ou uma entrevista para um meio de comunicação ou, ainda, e mais frequentemente, por ocasião das feiras de artesanato, sejam elas regionais, nacionais ou internacionais. Nestas situações, uma narrativa se torna constante: a noção de herança.

A ideia de "herança" é poderosa, e neste caso fora criada a partir de certa imaginação acerca do processo colonizador. Gonçalves (2005) observa que as ideias de patrimônio, a noção de propriedade e de herança referem-se às trajetórias e atuam como uma extensão dos indivíduos e das comunidades, englobando um campo simbólico e uma extensão moral, e, por isso, podem ser entendidas como uma construção que articula e expressa noções de identidade e de memória. Apresentam, ainda, a forma pela qual um grupo quer ser reconhecido.

Quase que majoritariamente, as entrevistas abriam com o discurso de uma herança portuguesa, especificamente madeirense, como responsável pelo desenvolvimento daquele estilo de bordado na região. Vieira (1988), ao historizar o processo migratório da Ilha da Madeira, narra que este território português funcionava como um porto de abastecimento, onde poder-se-ia também obter os bordados. Era um refúgio para tempestades e intempéries, reparo das naus e 
provisão de vinho, pescado e azeite. Pela sua centralidade nos processos comerciais, a Ilha da Madeira tinha um impacto político na Colônia. É possível que o fluxo migratório madeirense para o Brasil, no período colonial, tenha sido formado por soldados e agentes da burocracia régia, somados aos colonos para o arroteamento de terras e trabalhadores especializados para a construção de engenho (Santos 1999). Mas, até então, no conhecimento da autora, não há qualquer referência à migração feminina e, consequentemente, à produção de bordados madeirenses, no período colonial, naquele território brasileiro.

Fato é que houve uma presença portuguesa marcante no processo de ocupação deste território (Macêdo 2012). Foi em meados do século XVIII, que as mulheres chegaram à região como uma resposta à baixa taxa populacional no reino português que precisava viabilizar o processo de ocupação do território sertanejo, sob rígidos modelos ideológicos de cuidado com a família (Gomes 2004). Portanto, não é de se surpreender que seja no processo de colonização portuguesa que as bordadeiras filiam a sua trajetória, ainda que sem dados históricos que o comprovem.

A partir de um encontro das bordadeiras seridoenses com as madeirenses na Feira Internacional de Artesanato em Lisboa, em 2006, a narrativa da herança se tornou ainda mais poderosa. Tradicionalmente, as bordadeiras da Ilha da Madeira expõem neste evento, no entanto, pela primeira vez, as brasileiras participavam desta feira, podendo conhecer a estrutura do grupo de bordadeiras madeirenses, algumas de suas bordadeiras e, principalmente, o bordado feito na Ilha. Essa fora a primeira oportunidade que as bordadeiras seridoenses tiveram para comparar tão de perto a sua produção com as de além-mar. Deste evento em diante, pela sensação de similaridade e de projeção estética que as brasileiras experimentaram ao se encontrar com bordados portugueses, a narrativa sobre a herança portuguesa dos bordados de Caicó como um feito das primeiras colonizadoras do espaço seridoense, tornou-se real.

Ainda que não exista nenhuma constatação histórica da presença de mulheres madeirenses na região seridoense durante o período colonial, é interessante notar o quanto os bordados feitos nesta região de Portugal são compostos por elementos e estilos similares aos caicoenses, sobretudo pelos elementos florais, sendo que a flor que caracteriza o bordado de Caicó, no circuito dos bordados nordestinos, é semelhante à produzida na Ilha da Madeira. Além do mais, tal comparação entre coletivos de bordadeiras permite notar semelhanças significativas em vários níveis: pelo estilo dos pontos e uso de cores; pelo repertório dos bordados, organização dos motivos e composições para as peças, a partir de modelos figurativos e/ou geométricos. Como estas lógicas estéticas se entrecruzaram é uma das questões a que esta investigação se propõe responder.

Existem outras percepções sobre os bordados, além da própria estética, que apontam laços comuns. Assim como no Seridó, na Ilha da Madeira bordar era uma prática artesanal, doméstica e feminina, portanto, realizada majoritariamente nos lares, o que permitia conciliar o ato de bordar com a atividade agrícola e caseira e, ao mesmo tempo, atribuía um precário suplemento de dinheiro para a economia caseira, ou seja, bordar também era cuidar da família e do lar. Assim, até o final do século XIX, os bordados madeirenses eram feitos nos espaços domésticos para uso exclusivo do lar, um produto não vendável, que raramente saia do circuito familiar (Vieira 2006). 
Vieira (2006) destaca o fato de que foram os britânicos que perceberam a possível comercialização desses bordados produzidos em Portugal, a partir de uma exposição sobre a indústria madeirense, em Funchal, em abril de 1850. Em 1854, Miss Elisabeth Phelps, filha de um mercador de vinhos que havia visitado a exposição, passou a exportar os bordados produzidos na ilha, interessando-se, ainda, por criar uma escola para disseminação do ofício que teve um papel fundamental na economia da Ilha da Madeira, no século XIX, através de uma política específica de comercialização e de apuro técnico e estético (Vieira 2006).

A escola de Miss Phelps reunia referências na ornamentação dos tecidos advindas de regiões e de culturas distintas da realidade portuguesa, principalmente as referências orientais, os parâmetros artísticos em voga na Inglaterra, como o movimento ArtsE'Crafts e pré-Rafaelistas, sem, contudo, abandonar o rigor dos modelos da ética e da estética vitoriana. Além disso, o ambiente de encontro estético da escola de bordado visava, principalmente, o comércio profissionalizado e vocacionado para o mercado e a expansão internacional. Com isso, o bordado madeirense tornou-se uma importante forma de gerar riqueza para os comerciantes que estavam envolvidos no negócio, mas também funcionou como fonte de remuneração em complemento ao trabalho rural, tornando-se uma possibilidade viável de trabalho feminino, fundamental em momentos de crise na lavoura, principalmente, durante os primeiros anos do século XX quando a vinicultura, principal cultura da região, sofreu uma crise violenta (histórias semelhantes ocorreram com o bordado realizado em todo Seridó, por ocasião da crise algodoeira).

Desde as primeiras iniciativas da colonização do território brasileiro, por meio da implementação das famílias, os bordados são entendidos como produtos de luxo; e, apoiados nas análises de Sombart (1979), podemos entender que a produção e o consumo de bens de luxo estimularam a manufatura, o comércio e o acesso às mercadorias que poderiam inserir os brasileiros no movimento germinal da construção de um sistema global.

Era por meio dos bens de luxo, que as pessoas buscavam acessar conexões entre Ocidente, Oriente e o Novo Mundo. Essa diáspora comercial levava comunidades de comerciantes a moverem bens por entre fronteiras culturais que, até então, não haviam sido transpostas, os bens orientais se tornavam fonte de desejo - de leques às esculturas de marfim, das sedas à porcelana, passando pelas caixinhas de sândalos - e "passam a influenciar a vida, os costumes e a arquitetura no Brasil Colônia” (Freyre 1992: 59). Não é de se estranhar a relação/filiação que buscam as bordadeiras brasileiras.

A produção e circulação dos têxteis artesanais, bem como de seus ornamentos, se encontra em uma situação pendular. Ainda que ligados à ideia de amadorismo (Simioni 2010), alocando a produção dessa cultura material nas esferas de uma experiência estética considerada menor (se comparada às artes plásticas), há uma série de observações que apontam o lugar de destaque deste conhecimento tradicional no desenvolvimento econômico do capitalismo nascente.

Longas viagens que percorriam manufaturas e mercados da Europa, do Oriente e do Novo Mundo, conduziam os comerciantes à busca de símbolos de refinamento e de luxo para atender aos novos sentidos da sociedade moderna (Sombart 1979). Os têxteis, neste contexto, revelaram-se como um produto privilegiado nos acordos comerciais, inclusive sendo usados como moeda de troca no comércio das especiarias e de outros bens de luxo. No fluxo global colonial, as técnicas de criação, produção e circulação dos produtos têxteis puderam, ainda, misturar conhecimentos e gostos que pertenciam a lugares e culturas até então díspares. Isso promoveu um 
intercâmbio nas noções estéticas e nas metodologias produtivas ao incluir, por exemplo, novas cores e técnicas nas experiências nativas, assim como motivos e composições originais.

\section{MULHERES, BORDADOS E CIRCUITOS}

O olhar de Lévi-Strauss para o grafismo kadiwéu pode ser inspirador para esta análise (Lévi-Strauss 1989). Como lembra Severi (2011), o antropólogo aloca a experiência criativa da produção artística em um modelo de comunicação coletiva, uma vez que ele não acredita no "exercício criativo absoluto". A experiência criativa de um artesão, por exemplo, pode revelar uma habilidade de escolhas originais e de combinações que ocorrem no cerne de um repertório ideal rumo a uma "transposição qualitativa" da leitura sobre rituais, modelos culturais, formas de composição social da natureza, e sobre como estes repertórios podem ser compartilhados coletivamente por meio do uso criativo dos materiais, das técnicas e dos conceitos disponíveis.

As formas criativas da cultura material têxtil perpassam a experiência supracitada e a tornam pública pelo cuidado com a vida doméstica. Ao fazer isso, conduzem representações sobre a vida cotidiana e privada, mas não apenas. São objetos que se formam por encontros artísticos multiculturais e podem, ainda, revelar interpretações originais sobre experiências coletivas em um sentido mais amplo como a tecnologia, a produção e o comércio, testemunhando modelos de economia e política, bem como o processo de elaboração da História - e muitas outras histórias que eles acabam por testemunhar (Appadurai 2008).

Os objetos artesanais de linhas e agulhas são acompanhados por uma ética da paciência que se manifesta em uma estética impecável, em torno de uma sociabilidade e tempos femininos (Denis 2005); ora, as práticas artesanais engendram uma gama múltipla de ações que são desenvolvidas por processos de aprendizado, domínio de técnicas e de repertórios estéticos que as compõem. Incorporam, ainda, escolhas - que também são pessoais - e modos de lidar com um conhecimento que se refaz criativamente pelas gerações (Gordon 2004). Apenas para destacar uma destas práticas, aprender a bordar, por exemplo, apresenta uma relação contínua com a disciplina do corpo em prol da excelência do produto, estabelecida por um longo treino que vai além do ensino de bordar em si, moldando a forma de ser de uma bordadeira e criando uma cultura do bordado (Brito 2011).

Permanecendo neste movimento pendular e mediante a relevância cada vez maior dos tecidos e de seus ornamentos, como bordados, nos circuitos econômicos coloniais (ampliados pela industrialização nascente), é possível supor uma crescente alteração social no papel da mulher ou, como nas palavras de Sombart (1979), no "triunfo da mulher" diante das relações intrínsecas do mercado capitalista, potencializadas pelas circunstâncias do comércio ultramarino e expansionista. A mulher, então, naquele contexto, passou a ter uma "missão transformadora relevante", seja ela por meio da coquetterie ou através da produção disciplinada do sistema econômico (Villas Bôas 2000).

Portanto, do consolidar de determinados padrões de gosto e de comportamento feminino - sejam eles na intimidade das casas ou no mercado - ao trabalho silencioso das fábricas e dos lares, o que se observa é o processo cultural de uma prática artesanal, em constante circulação. Os tecidos - e suas ornamentações - fornecem uma visão impressionante de séculos de arte, de 
produção artesanal, de busca por excelência técnica, ética e estética, de encontros culturais, de expansão colonial e, no caso brasileiro, de processos de ocupação do território.

Kopytoff destaca que há uma "economia moral subjacente à economia das transações visíveis" (Kopytoff 2008: 88) e que é a cultura quem "assegura que algumas coisas permaneçam inconfundivelmente singulares", devido a uma classificação valorativa que tanto se relaciona com as características de uma determinada coisa, seus possíveis usos - ou não usos. Os bordados são tecidos adornados, mas são muito mais do que isso.

Esta arte doméstica, feminina, tradicional, apresenta releituras da natureza, do contexto vividos pelas artesãs, bem como dos olhares únicos e individualizados acerca de suas vidas, que assim o fazem por meio da produção e do embelezamento dos tecidos. Ainda que a experiência estética e a prática artesanal se ordenem a partir de uma vivência pessoal, a cultura artesanal abrange os mais variados relacionamentos que se tangenciam no processo de produção, promovendo a criação de vínculos em vários níveis, reunindo passado e presente em uma mesma peça e, assim, construindo uma forma de estar e de ver o mundo (Brito 2011).

Em uma linguagem maussiana, poderíamos intuir que essas peças estão sob o circuito da dádiva (Mauss 2003), cuja existência se desenvolve em alguns sentidos. Por exemplo, de um lado, trata-se de um objeto que existe a partir do conhecimento daquelas que produzem estes artefatos e, de outro, do papel daqueles que os consomem, uma vez que estes apontam para as propriedades da mercadoria e que as transcendem. Pode-se observar, ainda, que há um movimento de complementaridade, no qual certas mercadorias são envolvidas em um processo cognitivo e cultural, tendo, ainda, uso retórico e social. No circuito das transações comerciais, os bordados mantêm consigo algo de quem os fez, o nome e o prestígio da bordadeira. Seu valor obedece à lógica da "relação da bordadeira com a peça, os lugares e o contexto em que foi obtido, as situações nas quais serão usados, bem como os significados que lhes são atribuídos”, trazendo consigo "a história, a memória, a manutenção dos laços sociais" permitindo que as pessoas tenham o lugar consigo (Brito 2011: 262).

\section{CONSIDERAÇÕES FINAIS}

Se os bordados trazem possibilidades de distinção que se manifestam tanto no uso quanto nas suas chances de troca, colocando a provável mercantilização das coisas em outra lógica que transcende às da economia e a circulação de bens, é possível considerarmos que as situações de contato cultural podem, ainda, revelar uma pista importante para entendermos este objeto singular.

Deste modo, podemos observar esta questão em vários níveis: das inspirações estéticas que são reveladas pelas modas de uma época até a projeção das bordadeiras brasileiras a uma filiação madeirense para assegurar noções de autenticidade e de identidade regional; passando, ainda, pela perspectiva histórica das possibilidades de circulação das peças entre Oriente (incluindo as viagens às Índias), Inglaterra, Portugal e Brasil. Em outras palavras, não é à toa que aquele pedaço de tecido indiano me fizesse retomar temas que tratam da circulação, das diásporas, dos encontros e da vida das mulheres. 
A ideia de diáspora - que pouco apareceu por aqui - pode nos ser útil para refletir sobre os possíveis contatos culturais. Será que a biografia do bordado, narrada pelas bordadeiras caicoences acerca de sua herança madeirense, nos ajuda a refletir sobre o que torna significativa a adoção de determinadas referências e não outras (por que elas se filiaram aos bordados da Madeira e não dos açorianos, por exemplo). No mesmo exercício, pensar no que é significativo para os madeirenses adotar a referência inglesa, e por aí vai. Estamos, provavelmente, diante da elaboração de uma biografia das coisas, no sentido em que Kopytoff (2008) nos alerta. Nesse sentido, vale pensar sobre "o que é significativo sobre a adoção de objetos estrangeiros - e ideias estrangeiras - não é a sua adoção, mas sim a maneira pela qual eles são culturalmente redefinidos e colocados em uso". (Kopytoff 2008: 94).

Nosso interesse não é propor, de modo algum, uma arqueologia ou mapear reminiscências da história - ainda que este fosse um trabalho bem bonito - mas como esses aspectos simbólicos vão criando aderência e trazendo sentidos para aquilo que se faz. Assim, ainda que o bordado seja um objeto comercializado em feiras específicas e que atendam a públicos e interesses diferentes, ele circula não apenas como uma mercadoria, mas como uma "entidade dotada de significados culturalmente específicos e classificada e reclassificada em categorias culturalmente constituídas" (Kopytoff 2008: 94).

\section{REFERÊNCIAS BIBLIOGRÁFICAS}

Appadurai, A. (ed.). 2008. A vida social das coisas. As mercadorias sob uma perspectiva cultural. Niterói: Editora da UFF.

Baudrillard, Jean. 2002. O sistema dos objetos. São Paulo: Perspectiva.

Bittencourt, Luciana. 1996. Spinning Lives. Lanham, Maryland: University Press of America. Borges, Maria Eliza L. 2011. "Cultura dos ofícios: patrimônio cultural, história e memória". Revista Varia História, v. 46, pp. 481-508, jul./dez.

Brito, Thaís F. S. 2011. Bordados e bordadeiras. Um estudo sobre a produção artesanal de bordados em Caicó/RN. Tese (Doutorado em Antropologia Social). São Paulo: Universidade de São Paulo, São Paulo.

2017. Sertão de Caicó: um breve ensaio sobre homens, currais e bordados - de memórias aos novos temas para o masculino. Mneme. Revista de Humanidades. v.17. n. 39,p. 58-81, maio 2017.

Cavignac, Julie A.; Alves, Maria Lúcia. B. Sant’Anna de Caicó, avó do sertão: festa, turismo religioso e patrimônio cultural do Seridó (RN). In: Encontro Anual da Anpocs, 31, 2007, Caxambu, Anais eletrônicos... Caxambu: ANPOCS, 2007. Mesa Redonda. Disponível em https://anpocs.com/index.php/papers-31-encontro/st-7/st06-6/2796-bastos-cavignac-santanna-de/file, consultado em 02/02/2019.

Denis, Maria N. 2005. Les brodeuses d'autrefois. In: Gatineau, Barbara; Tourscher, Alexadre (org). Broder sans compter. L'Art de la broderieen Alsacesu 16e au 20e siècle. Strasbourg: Les Musées de Strasbourg.

Freyre, Gilberto. 1992. Casa Grande e Senzala. São Paulo: Editora Record, 31ª edição. Gell, Alfred. 1998. Art and Agency: An Anthropological Theory. Oxford: Clarendon Press.

Gomes, Regina. 2004. Quer casar? Aprenda a bordar ... e depois, por que não comercializar? Revista Museu do Seridó. Caicó: Museu do Seridó/UFRN/PROEX/CERES. 
Gonçalves, José Reginaldo G. S. 2005. Ressonância, imaterialidade e subjetividade. As culturas como patrimônio. Horizontes Antropológicos. Porto Alegre, ano 11, n. 13, pp. 15-35, jan/ jun.

IBGE. Instituto Brasileiro de Geografia e Estatística. 2018. I Pesquisa Nacional por Amostra de Domicílios. Rio de Janeiro: IBGE. Disponível em https://cidades.ibge.gov.br/brasil/rn/ caico/panorama. Acesso em 02/02/2019.

Ingold, Tim. 2007. Lines. A brief history. London/NewYork: Routledge. . 2012. Trazendo as coisas de volta à vida. Horizontes antropológicos. Porto Alegre, ano 18, n. 37, pp. 25-44, jan/jun.

Kopytoff, Igor. 2008. A biografia cultural das coisas: a mercantilização como processo. Em Appadurai, A. (ed.). A vida social das coisas. As mercadorias sob uma perspectiva cultural. Niterói: Editora da UFF, pp. 89-124.

Lévi-Strauss, Claude. 1989. O pensamento selvagem. São Paulo: Papirus editora.

Macedo, Helder. 2012. Sertões do Seridó: Estudos de História Colonial. Carnaúba dos Dantas: Bookess Editora.

Mauss, Marcel. 2003. Sociologia e antropologia. São Paulo: Cosac \&Naïf.

Neira, Luiz García. 2011. Discursos distintivos a partir da cultura material têxtil no Brasil (1847-1910). Revista Estudos Históricos. Rio de Janeiro, v. 24, pp. 284-304, jul/dez.

Piñon, Nélida. 2004. Vozes do deserto. Rio de Janeiro: Editora Record.

Queiroz, Karine G. 2013. O tecido encantado: o quotidiano, o trabalho e a materialidade do bordado. O cabo dos trabalhos: Revista eletrônica dos programas de doutoramento do CES/ FEUC/FLUC/III, Coimbra, n. 5, 2011. Disponível em: <http://cabodostrabalhos.ces. uc.pt/n5/documentos/5_KarineQueiroz.pdf>. Acesso em: 17 set. 2013.

Santos, Maria Licínia F. dos. 1999. Os madeirenses na colonização do Brasil. Dissertação (Mestrado em História da Expansão Portuguesa). Funchal: Centro de Estudos de História do Atlântico.

Severi, Carlo. 2011. A ideia, a série e a forma: desafios da imagem no pensamento de Claude Lévi-Strauss. Revista Sociologia E Antropologia. V. 01.02, pp. 53-75.

Simioni, Ana. 2010. Bordado e Transgressão: questões de gênero na arte de Rosana Paulino e Rosana Palazyan. Proa - Revista de Antropologia e Arte, v. 1, n. 2, 2010. Disponível em http:// www.ifch.unicamp.br/proa/ArtigosII/PDFS/anasimioni.pdf. Acesso em 19/9/2013.

Sombart, Werner. 1979. Lujo y capitalismo. Madrid: Alianza Editorial.

Vieira, Alberto. 1988. Na rota dos descobrimentos e a expansão atlântica. Lisboa: Instituto de investigação científica tropical. 2006. Bordado da Madeira. Funchal: Bordal.

\section{NARRATIVES AND EMBROIDERY FABRICS}

The aim of this article is to present embroideries that transcend the notion of commodities, becoming a singular object and a cultural asset, fruit of artistic techniques that combine materiality and sensibility, mobilities and diasporas, personal and collective readings of the artisanal practices of production. The analysis is based on narratives of embroiderers of Caico- $R N$, Brazil, and their discourses on the aesthetics of their embroideries, as revealed by the representations of the fabrics. The article proposes a 
reflection on the anthropological knowledge regarding a number of elements linked to textile material culture.

Keywords: textile culture, narratives, diasporas, clothing, artefacts

Recebido em: 2018-08-01

Aceitado em: 2019-03-13 